\title{
Lin28/let-7/Bcl-xL pathway: The underlying mechanism of drug resistance in Hep3B cells
}

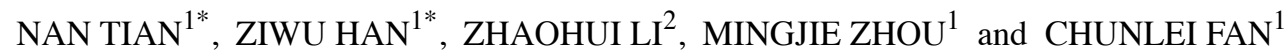 \\ ${ }^{1}$ College of Life Science, Zhejiang Chinese Medical University, Hangzhou, Zhejiang; \\ ${ }^{2}$ Department of Neurosurgery, China-Japan Union Hospital, Jilin University, Changchun, Jilin, P.R. China
}

Received March 16, 2014; Accepted April 22, 2014

DOI: $10.3892 /$ or.2014.3292

\begin{abstract}
Hepatocellular carcinoma (HCC) is highly resistant to chemotherapeutic drugs, which markedly reduces the effect of chemotherapy. Lin28 has been shown to contribute to tumor relapse after chemotherapy; however, the relationship between Lin28 and chemotherapy drug resistance is unknown. In the present study, we established a drug-resistant Hep3B cell line to investigate the association between $\operatorname{Lin} 28$ and drug resistance in HCC, and we identified the underlying mechanisms. We found that the expression of Lin 28 was closely associated with resistance to paclitaxel. The drug-resistant Hep3B cell line, which expresses high levels of Lin28, is more resistant to paclitaxel and other anticancer drugs than the parental cell line. Moreover, further studies showed that dysregulation of Lin28 inhibited let-7 family microRNA levels and upregulated the anti-apoptotic protein Bcl-xL, which is a target of let-7. Our results indicate that the Lin28/let-7/Bcl-xL pathway underlies the drug resistance of Hep3B cells.
\end{abstract}

\section{Introduction}

Hepatocellular carcinoma (HCC) is one of the most frequently occurring malignancies in Asia, due to the endemic status of chronic hepatitis $\mathrm{B}$ and $\mathrm{C}$ virus infection (1). The onset of $\mathrm{HCC}$ is insidious, and no symptoms occur in the early stages. Surgical removal is not suitable for most patients with HCC; therefore, transcatheter arterial chemoembolization (TACE)

Correspondence to: Professor Chunlei Fan, College of Life Science, Zhejiang Chinese Medical University, 548 Binwen Road, Binjiang, Hangzhou, Zhejiang 310053, P.R. China

E-mail: shuiguolanzi1983@126.com

*Contributed equally

Abbreviations: DMEM, Dulbecco's modified Eagle's medium; FBS, fetal bovine serum; FCM, flow cytometry analysis; HCC, hepatocellular carcinoma; MTT, 3-(4,5-dimethylthiazol-2-yl)-2,5diphenyltetrazolium bromide; TACE, transcatheter arterial chemoembolization

Key words: hepatocellular carcinoma, Lin28, let-7 family, Bcl-xL, drug resistance has become the mainstay of treatment (2). However, hepatoma cells are known to be highly resistant to chemotherapeutic drugs (3). This severely reduces the effects of TACE. Thus, there is an urgent need to determine the drug resistance mechanism in HCC.

Lin28, a well-known cancer stem cell marker (4), has become a popular target of researchers in recent years. Several studies have demonstrated that high expression of Lin 28 correlates with resistance to chemotherapy in breast and gastric cancer $(5,6)$. Since Lin28 is also highly expressed in HCC (7), we investigated whether high Lin 28 expression is also related to drug resistance in HCC. Lin28 is an RNA binding protein that blocks the biogenesis of let-7 by inducing terminal uridylation and degradation of let-7 precursors $(8,9)$. Downregulation of let-7 promotes the expression of Bcl-xL, an anti-apoptotic gene; overexpression of Bcl-xL always induces apoptosis resistance and reduces the sensitivity of tumor cells to drugs (10). Here, we examined whether Lin28-mediated dysregulation of the Lin28/let-7/Bcl-xL pathway is involved in the drug resistance of $\mathrm{HCC}$.

In the present study, we established a drug-resistant Hep3B cell line (Hep3B/TAX) by stepwise sequential exposure to increasing concentrations of paclitaxel to analyze the relationship between Lin28, the let-7 family, Bcl-xL and the drug resistance in HCC. The aim of the present study was to gain insight into the molecular mechanisms of chemoresistance and to provide a potential target to overcome chemoresistance in HCC.

\section{Materials and methods}

Chemicals and reagents. Paclitaxel was purchased from Tianjin YiFang Science and Technology, Ltd. (Tianjin, China). 5-Fluorouracil injection, cisplatin and cytoxan were obtained from Zhejiang Chinese Medical University Second Clinical Medical College. Antibodies against Lin 28 and $\beta$-actin, and horseradish peroxidase-conjugated secondary antibodies were purchased from Boster Biological Technology, Ltd. (Wuhan, China). Antibodies against caspase-3 and -9, BAX, cytochrome $c, \mathrm{Bcl}-2$ and $\mathrm{Bcl}-\mathrm{xL}$ were purchased from Hangzhou HuaAn Biotechnology Co., Ltd. (Hangzhou, China). Dulbecco's modified Eagle's medium (DMEM), fetal bovine serum (FBS), and other tissue culture reagents were purchased from Beijing Dingguo Changsheng Biotechnology 
Co., Ltd. (Beijing, China). TRIzol reagent was purchased from Invitrogen (Carlsbad, CA, USA). HiFi-MMLV cDNA kits and UltraSYBR Mixture were obtained from Beijing Kang Century Biotechnology Co., Ltd. (Beijing, China).

Cell culture. The human hepatoma cell line Hep3B was obtained from Boster Biological Technology, Ltd., and was routinely cultured in DMEM supplemented with $10 \% \mathrm{FBS}$, penicillin $(100 \mathrm{U} / \mathrm{ml})$ and streptomycin $(100 \mathrm{mg} / \mathrm{ml})$ at $37^{\circ} \mathrm{C}$ and $5 \% \mathrm{CO}_{2}$.

Development of a paclitaxel-resistant cell line (Hep3B/TAX). To develop a paclitaxel-resistant HCC cell line, Hep3B cells were exposed to gradually increasing concentrations of paclitaxel (0.01-0.2 $\mu \mathrm{M})$ in complete medium. Briefly, Hep3B cells were seeded in culture flasks at a density of $4-5 \times 10^{5}$ cells $/ \mathrm{ml}$ and allowed to grow. After $24 \mathrm{~h}$ incubation, paclitaxel $(0.01 \mu \mathrm{M})$ was added, and the cells were incubated for another $24 \mathrm{~h}$. Then, the cells were washed 3 times with D-Hanks solution and the medium was changed to paclitaxel-free medium. The cells were incubated and allowed to grow until confluent. Then, the cells were subcultured and re-exposed to double the dose of drug. This process was repeated until the cells were resistant to $0.2 \mu \mathrm{M}$ paclitaxel. After successful development, Hep3B/TAX cells were maintained in complete medium containing a low concentration of paclitaxel $(0.01 \mu \mathrm{M})$.

Morphological examination of the drug-resistant Hep $3 B / T A X$ cells. Hep3B and Hep3B/TAX cells were seeded in $35 \mathrm{~mm}$ petri plates at a density of $1 \times 10^{5}$ cells $/ \mathrm{ml}$. After $24 \mathrm{~h}$ incubation, cells were visualized and photographed under a Nikon Eclipse 80i microscope connected to a DS-5M-L1 camera.

Cell viability assay. A previously described 3-(4,5-dimethylthiazol-2-yl)-2,5-diphenyltetrazolium bromide (MTT) uptake method (11) was used to determine the effect of drugs on the proliferation and viability of Hep3B and Hep3B/TAX cells. Experiments were repeated three times with 6 wells for each treatment to ensure the reproducibility of results. The $\mathrm{IC}_{50}$ value was defined as the dose of the drug required to inhibit cell growth by $50 \%$ and was calculated using the improved Karber's method.

Flow cytometry analysis (FCM). To determine whether Hep3B/TAX cells were more resistant to paclitaxel than the parental Hep3B cells, Hep3B/TAX and Hep3B cells were seeded in $35 \mathrm{~mm}$ petri plates at a density of $1 \times 10^{5}$ cells $/ \mathrm{ml}$. After $24 \mathrm{~h}$ incubation, cells were treated with paclitaxel for another $24 \mathrm{~h}$, and untreated cells served as control. Next, the cells were washed twice with PBS and resuspended in $100 \mu \mathrm{l}$ incubation buffer (PBS buffer containing 2\% BSA and 2\% FBS), and $100 \mu 1$ of Guava Nexin reagent was added. After incubation for $20 \mathrm{~min}$ at RT in the dark, all the samples were filtered sequentially through $200 \mu \mathrm{m}$ mesh sieves and analyzed using Guava EasyCyte 8 flow cytometer (EMD Millipore, USA). Annexin V-PE-negative and 7-AAD-negative cells were considered alive.

Quantitative real-time PCR. Total RNA was isolated using TRIzol reagent according to the manufacturer's instructions.
cDNA was synthesized using a HiFi-MMLV cDNA kit. To synthesize let-7 family cDNAs, specific RT-primers were used that were based on the sequence of each family member, and the RT-primer for U6 was the same as the reverse primer (Table I). Real-time PCR was conducted using UltraSYBR Mixture. All primers were synthesized by GenScript Co., Ltd. (Nanjing, China). All samples were run in triplicate, and changes in gene expression were calculated using the $\Delta \Delta \mathrm{Ct}$ method.

Western blot analysis. Total protein was extracted from cells using Protein Extraction Reagent (Boster Bioengineering, Wuhan, China) containing $1 \mathrm{mM}$ phenylmethanesulfonyl fluoride (PMSF) (Roche Molecular Biochemicals, Indianapolis, IN, USA). Protein concentrations were determined by the BCA protein assay (Nanjing KeyGen Biotech Co. Ltd., Nanjing, China). The proteins were separated by $10 \%$ SDS-PAGE and transferred to a polyvinylidene difluoride (PVDF) membrane (Pall Gelman Laboratory Corporation, Ann Arbor, MI, USA). Then, the western blot analyses were probed with antibodies against Lin28, caspase-3 and -9, BAX, cytochrome $c$, Bcl-2, Bcl-xL and $\beta$-actin. The protein bands were detected by enhanced chemiluminescence.

Statistical analysis. Data are expressed as means \pm SD of experiments performed in triplicate. Statistical analysis was performed using one-way analysis of variance (ANOVA) for multiple comparisons and t-tests for comparisons between groups. A P-value of $<0.05$ was considered to indicate a statistically significant difference.

\section{Results}

Establishment of the Hep3B/TAX cell line. A human hepatoma paclitaxel-resistant model system was established, as described in the Materials and methods section, to study the molecular mechanisms of drug resistance. After 9 months of development, we obtained Hep3B/TAX cells that grew stably in DMEM containing $0.2 \mu \mathrm{M}$ paclitaxel. Microscopic observation showed that the Hep3B/TAX cells were elongated compared with their parental cells, especially at low cell density (Fig. 1A, a-1 and a-2), and the number of black particles in cytoplasm of Hep3B/TAX cells increased (Fig. 1A, b-1 and b-2). The doubling time for Hep3B was $44.21 \pm 1.47 \mathrm{~h}$ and that of Hep3B/TAX cells was $49.16 \pm 1.89 \mathrm{~h}$, therefore the growth rate of paclitaxel-resistant cells was significantly lower than that of the parental cells (Fig. 1B, P<0.01). Next, to determine the $\mathrm{IC}_{50}$ value of paclitaxel, Hep3B and Hep3B/ TAX cells were treated with various doses of paclitaxel for $48 \mathrm{~h}$ and then cell viability was assessed using the MTT assay. As shown in Fig. 2A, we found that the survival rate of Hep3B/TAX cells was much higher than that of their parental cells after treatment with the same dose of paclitaxel. The $\mathrm{IC}_{50}$ values were $0.2 \mu \mathrm{M}$ for Hep3B cells and $5.65 \mu \mathrm{M}$ for Hep3B/TAX cells at $48 \mathrm{~h}$, and the drug resistance index was 28.25 (Table II). These data suggest that Hep3B cells are more sensitive to paclitaxel than Hep3B/TAX cells. We also assessed the response of Hep3B and Hep3B/TAX cells to other chemical drugs besides paclitaxel, and we found that Hep3B/ TAX cells exhibited cross-resistance to cisplatin, 5-fluorouracil and cytoxan (Fig. 2B-D and Table II). 
Table I. Primer pairs used for quantitative real-time PCR.

\begin{tabular}{|c|c|c|}
\hline Gene & Primer name & Sequences $\left(5^{\prime}-3^{\prime}\right)$ \\
\hline Let-7a & $\begin{array}{l}\text { RT-primer } \\
\text { Forward primer }\end{array}$ & $\begin{array}{l}\text { GTTGGCTCTGGTGCAGGGTCCGAGGTATTCGCACCAGAGCCAACAACTAT } \\
\text { CGGTGAGGTAGTAGGTTGT }\end{array}$ \\
\hline Let- $7 b$ & $\begin{array}{l}\text { RT-primer } \\
\text { Forward primer }\end{array}$ & $\begin{array}{l}\text { GTTGGCTCTGGTGCAGGGTCCGAGGTATTCGCACCAGAGCCAACAACCAC } \\
\text { CGGTGAGGTAGTAGGTTGT }\end{array}$ \\
\hline Let-7c & $\begin{array}{l}\text { RT-primer } \\
\text { Forward primer }\end{array}$ & $\begin{array}{l}\text { GTTGGCTCTGGTGCAGGGTCCGAGGTATTCGCACCAGAGCCAACAACCAT } \\
\text { CGGTGAGGTAGTAGGTTGT }\end{array}$ \\
\hline Let-7d & $\begin{array}{l}\text { RT-primer } \\
\text { Forward primer }\end{array}$ & $\begin{array}{l}\text { GTTGGCTCTGGTGCAGGGTCCGAGGTATTCGCACCAGAGCCAACAACTAT } \\
\text { CGCCGAGAGGTAGTAGGTTGC }\end{array}$ \\
\hline Let-7e & $\begin{array}{l}\text { RT-primer } \\
\text { Forward primer }\end{array}$ & $\begin{array}{l}\text { GTTGGCTCTGGTGCAGGGTCCGAGGTATTCGCACCAGAGCCAACAACTAT } \\
\text { CGGTGAGGTAGGAGGTTGT }\end{array}$ \\
\hline Let-7f & $\begin{array}{l}\text { RT-primer } \\
\text { Forward primer }\end{array}$ & $\begin{array}{l}\text { GTTGGCTCTGGTGCAGGGTCCGAGGTATTCGCACCAGAGCCAACAACTAT } \\
\text { CGGTGAGGTAGTAGATTGT }\end{array}$ \\
\hline Let-7g & $\begin{array}{l}\text { RT-primer } \\
\text { Forward primer }\end{array}$ & $\begin{array}{l}\text { GTTGGCTCTGGTGCAGGGTCCGAGGTATTCGCACCAGAGCCAACAACTGT } \\
\text { CGCCGTGAGGTAGTAGTTTGT }\end{array}$ \\
\hline Let-7i & $\begin{array}{l}\text { RT-primer } \\
\text { Forward primer }\end{array}$ & $\begin{array}{l}\text { GTTGGCTCTGGTGCAGGGTCCGAGGTATTCGCACCAGAGCCAACAACAGC } \\
\text { CGCCGTGAGGTAGTAGTTTGT }\end{array}$ \\
\hline Mir-98 & $\begin{array}{l}\text { RT-primer } \\
\text { Forward primer }\end{array}$ & $\begin{array}{l}\text { GTTGGCTCTGGTGCAGGGTCCGAGGTATTCGCACCAGAGCCAACAACAAT } \\
\text { CGGTGAGGTAGTAAGTTGT }\end{array}$ \\
\hline Universal & Reverse primer & GTGCAGGGTCCGAGGT \\
\hline U6 & $\begin{array}{l}\text { Forward primer } \\
\text { Reverse primer }\end{array}$ & $\begin{array}{l}\text { CTCGCTTCGGCAGCACA } \\
\text { AACGCTTCACGAATTTGCGT }\end{array}$ \\
\hline $\operatorname{Lin} 28$ & $\begin{array}{l}\text { Forward primer } \\
\text { Reverse primer }\end{array}$ & $\begin{array}{l}\text { CGGCCAAAAGGAAAGAGCAT } \\
\text { GTTGGCTTTCCCTGTGCACT }\end{array}$ \\
\hline $\mathrm{Bcl}-2$ & $\begin{array}{l}\text { Forward primer } \\
\text { Reverse primer }\end{array}$ & $\begin{array}{l}\text { CCAAGAATGCAAAGCACATCCA } \\
\text { GGTTATCGTACCCTGTTCTCCC }\end{array}$ \\
\hline $\operatorname{Bax}$ & $\begin{array}{l}\text { Forward primer } \\
\text { Reverse primer }\end{array}$ & $\begin{array}{l}\text { CAGCTGACATGTTTTCTGACGG } \\
\text { AATGTCCAGCCCATGATGGTT }\end{array}$ \\
\hline$\beta$-actin & $\begin{array}{l}\text { Forward primer } \\
\text { Reverse primer }\end{array}$ & $\begin{array}{l}\text { GGCACCACACCTTCTACAAT } \\
\text { GTGGTGGTGAAGCTGTAGCC }\end{array}$ \\
\hline
\end{tabular}
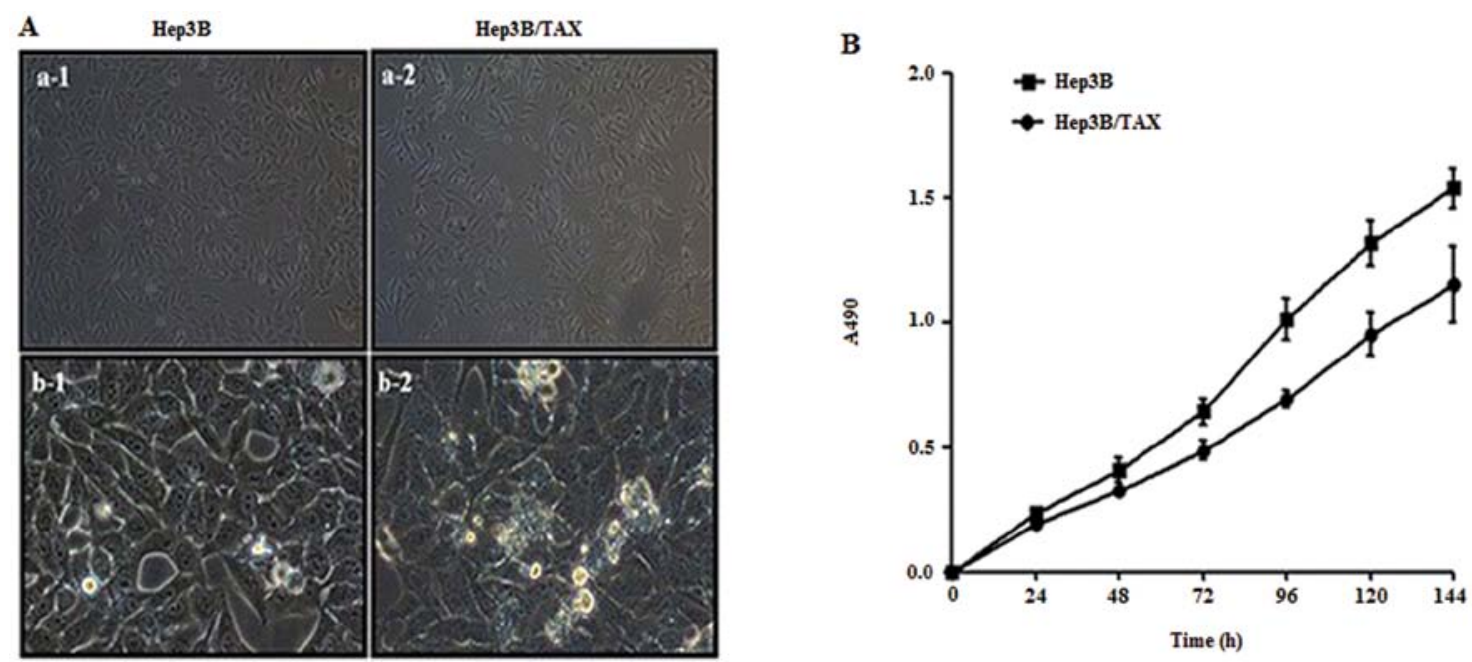

Figure 1. Establishment of paclitaxel-resistant cells (Hep3B/TAX). (A) Hep3B and Hep3B/TAX cells were observed under a microscope, (a-1 and a-2, x100); (b-1 and b-2, x400). (B) The growth curve of Hep3B and Hep3B/TAX cells. Cells $\left(2 \times 10^{3}\right)$ were plated in 96 -well plates and medium was removed at indicated time intervals and cell survival was evaluated by MTT assay. 

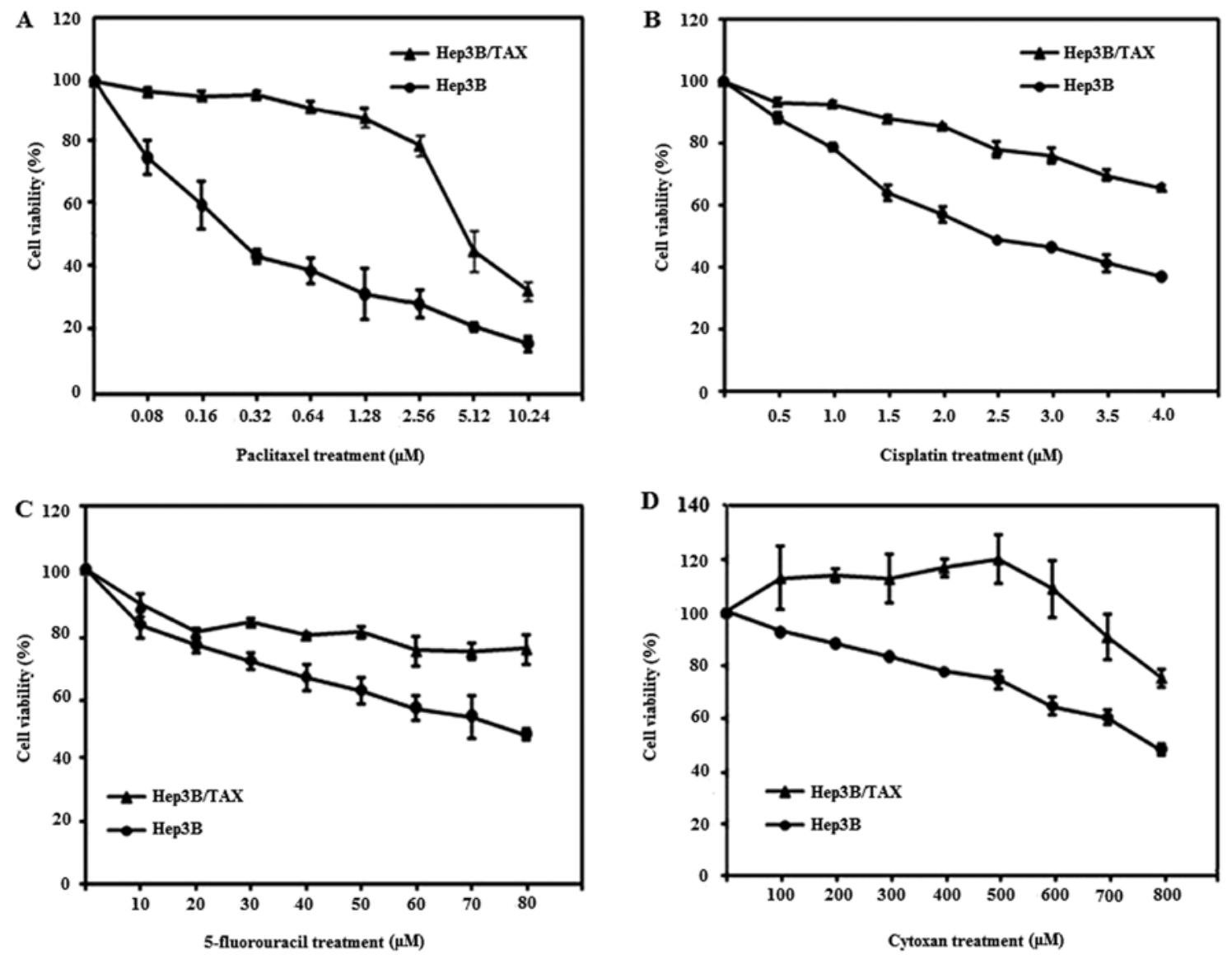

Figure 2. Effect of anticancer drugs on cell viability of Hep3B and Hep3B/TAX cells. Cell viability was assessed by MTT assay after $48 \mathrm{~h}$ of treatment with different concentrations of (A) paclitaxel, (B) cisplatin, (C) 5-fluorouracil and (D) cytoxan. The results are provided as means \pm SD from at least 3 independent experiments.

Table II. Response of Hep3B and Hep3B/TAX cell lines to various anticancer drugs.

\begin{tabular}{lccc}
\hline & \multicolumn{2}{c}{$\mathrm{IC}_{50}(\mu \mathrm{g} / \mathrm{ml})$} & \\
\cline { 2 - 3 } $\begin{array}{l}\text { Anticancer } \\
\text { drug }\end{array}$ & Hep3B & Hep3B/TAX & $\begin{array}{c}\text { Resistance } \\
\text { index }\end{array}$ \\
\hline Paclitaxel & 0.2 & 5.65 & 28.250 \\
Cisplatin & 2.976 & 6.591 & 2.215 \\
5-Fluorouracil & 64.874 & 148.431 & 2.288 \\
Cytoxan & 712.582 & 2407.008 & 3.378 \\
\hline
\end{tabular}

Apoptosis resistance of Hep3B/TAX cells and expression of apoptosis-related genes. After $24 \mathrm{~h}$ exposure to paclitaxel in DMEM, Hep3B and Hep3B/TAX cells were harvested, and their apoptosis rates were determined. As shown in Fig. 3, we observed that untreated Hep3B and Hep3B/TAX cells both showed very low apoptosis rates $(1.55 \pm 0.55$ and $2.41 \pm 0.69 \%$, respectively; Table III). After treatment with paclitaxel, the percentage of apoptotic Hep3B cells markedly increased to $21.65 \pm 2.28 \%(0.1 \mu \mathrm{M})$ and $30.57 \pm 4.74 \%(0.4 \mu \mathrm{M})$, whereas the apoptosis rate in Hep3B/TAX cells was still very low, only $2.63 \pm 0.87,3.82 \pm 0.99$ and $3.55 \pm 0.57 \%$ following treatment with $0.1,0.2$ and $0.4 \mu \mathrm{M}$ paclitaxel. Therefore, compared with Hep3B cells, Hep3B/TAX cells were much less sensitive to paclitaxel.
Table III. Rate of apoptosis in Hep3B and Hep3B/TAX cells induced by paclitaxel.

\begin{tabular}{lcrrr}
\hline & \multicolumn{4}{c}{ Dose of paclitaxel $(\mu \mathrm{M})$} \\
\cline { 2 - 5 } Cell type & $0(\%)$ & $0.1(\%)$ & $0.2(\%)$ & $0.4(\%)$ \\
\hline Hep3B & $1.55 \pm 0.55$ & $21.65 \pm 2.28^{\mathrm{a}}$ & $23.39 \pm 4.24^{\mathrm{a}}$ & $30.57 \pm 4.74^{\mathrm{a}}$ \\
Hep3B/ & $2.41 \pm 0.69$ & $2.63 \pm 0.87^{\mathrm{b}}$ & $3.82 \pm 0.99^{\mathrm{b}}$ & $3.55 \pm 0.57^{\mathrm{b}}$ \\
TAX & & & & \\
\hline
\end{tabular}

Numerical data are expressed as means \pm SD from 3 results. ${ }^{a} \mathrm{P}<0.001$ compared with untreated cells; ${ }^{\mathrm{b}} \mathrm{P}<0.001 \mathrm{Hep} 3 \mathrm{~B} / \mathrm{TAX}$ compared with Hep3B cells.

Activation of caspases is a hallmark of apoptosis; to measure this, Hep3B and Hep3B/TAX cells were treated with $0.2 \mu \mathrm{M}$ paclitaxel for $24 \mathrm{~h}$, and whole cell extracts were prepared and caspase- 9 and -3 activation was assessed. Western blot analysis showed that cleavage of caspase- 9 and -3 in Hep3B/TAX was reduced (Fig. 4A). Furthermore, we found that in Hep3B/TAX cells, the expression of Bax was reduced whereas the expression of anti-apoptosis protein Bcl-2 was enhanced (Fig. 4A), and real-time PCR analysis confirmed these findings (Fig. 4B). These results indicated that Hep3B/TAX cells are resistant to 

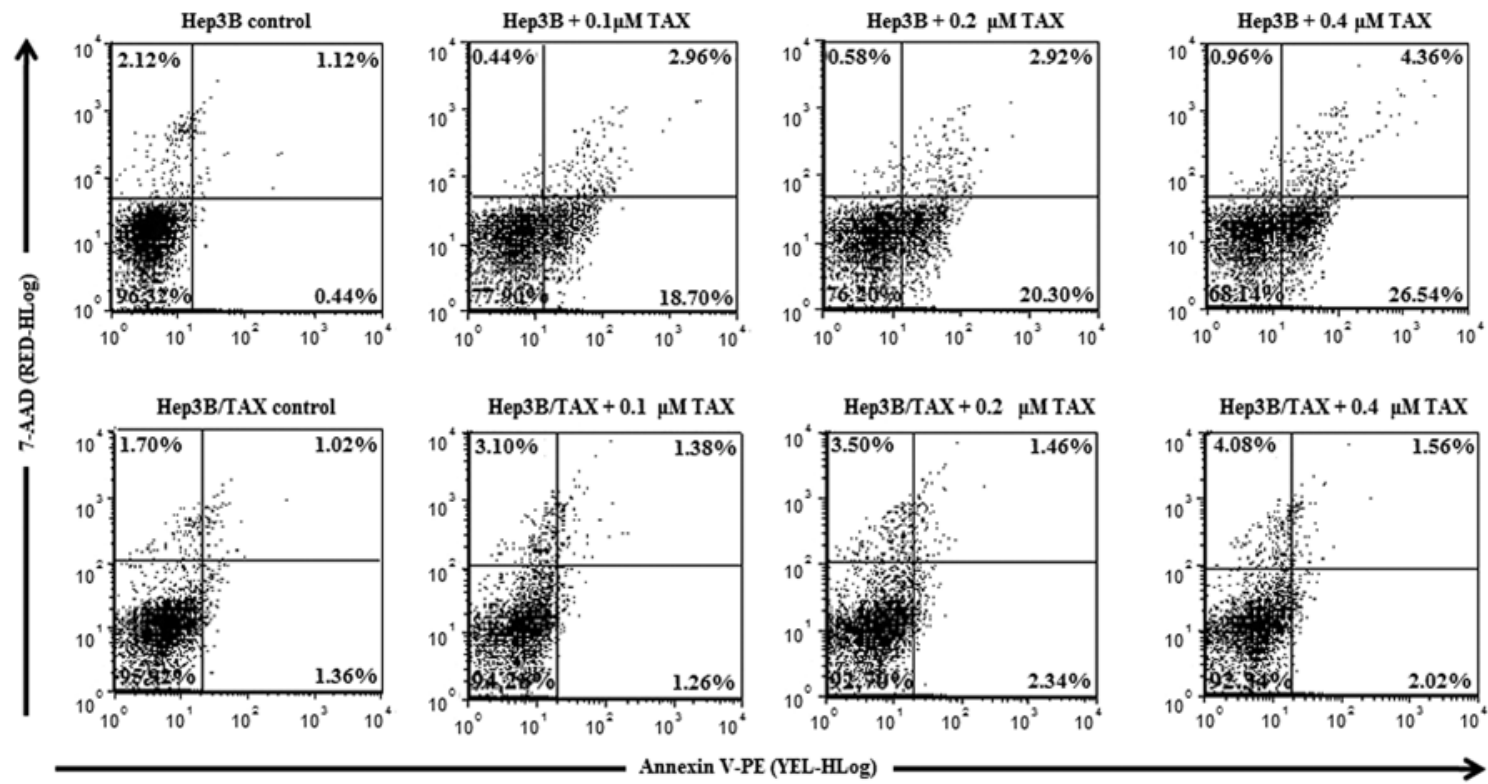

Figure 3. Induction of apoptosis in Hep3B and Hep3B/TAX cells treated with paclitaxel. Hep3B and Hep3B/TAX cells were incubated exclusively in DMEM culture medium or were treated with different concentrations of paclitaxel for $24 \mathrm{~h}$. After incubation, apoptosis was assessed using Annexin V-PE/7-AAD.

A

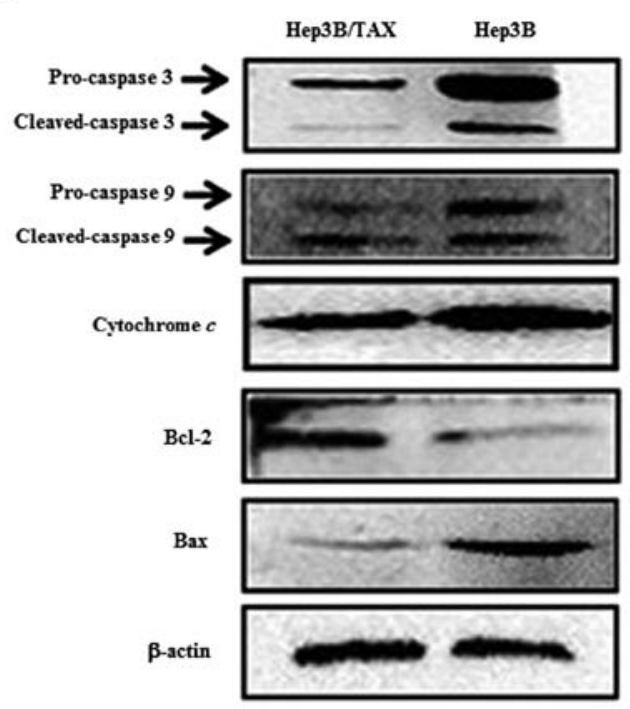

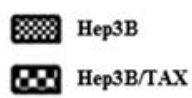

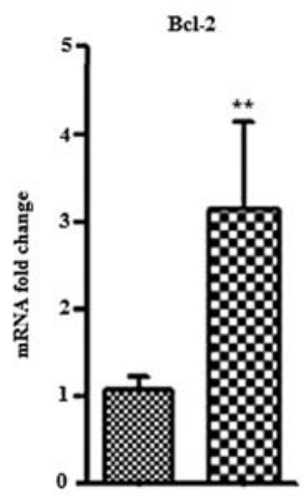

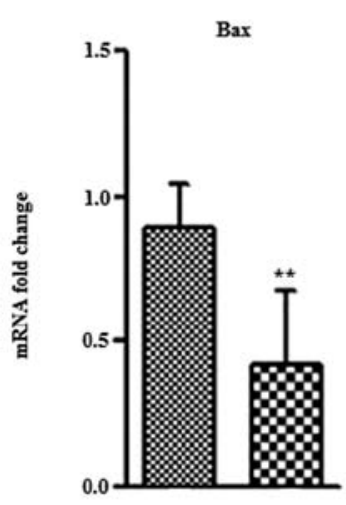

Figure 4. Expression of pro- and anti-apoptotic genes in Hep3B and Hep3B/TAX cells. (A) Western blot analysis of caspase-3,-9, Bcl-2 and Bax in Hep3B and Hep3B/TAX cells. (B) qPCR analysis of Bcl-2 and Bax in two cell lines. ${ }^{* *} \mathrm{P}<0.001$ Hep3B/TAX compared with Hep3B cells.

paclitaxel-induced apoptosis. Although this phenotype may be related to drug resistance, it nevertheless confirmed the successful development of a drug-resistant cell line.

Lin28/let-7/Bcl-xL is associated with drug resistance in Hep $3 B$ cells. To determine whether Lin 28 expression is associated with the drug resistance observed in $\mathrm{HCC}$, we examined the expression of Lin28 in Hep3B and paclitaxel-resistant Hep3B/TAX cells by qPCR. We found that the mRNA level of Lin28 in the paclitaxel-resistant cell line was 75-fold higher than that in the parental Hep3B cells (Fig. 5A) and the Lin28 protein level in Hep3B/TAX cells was also much higher than that in Hep3B cells (Fig. 5B). Then, we measured the expression of let-7 family miRNAs, which are regulated by Lin 28 . The results showed that the expression of all the let-7 family members tested was reduced except let-7b (Fig. 5C). The anti-apoptotic protein Bcl-xL plays a transcendental role in chemoresistance in tumor cells, and $\mathrm{Bcl}-\mathrm{xL}$ is regulated by let-7. Therefore, we examined the expression of Bcl-xL both in Hep3B and Hep3B/TAX cells by western blotting. We observed that the level of Bcl-xL protein was much higher in Hep3B/TAX cells than in Hep3B cells. All the data suggest that the Lin28/let-7/Bcl-xL pathway is associated with drug resistance in Hep3B cells. 


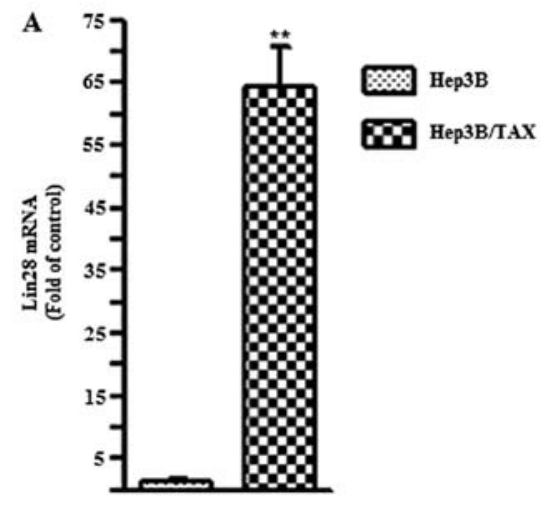

B

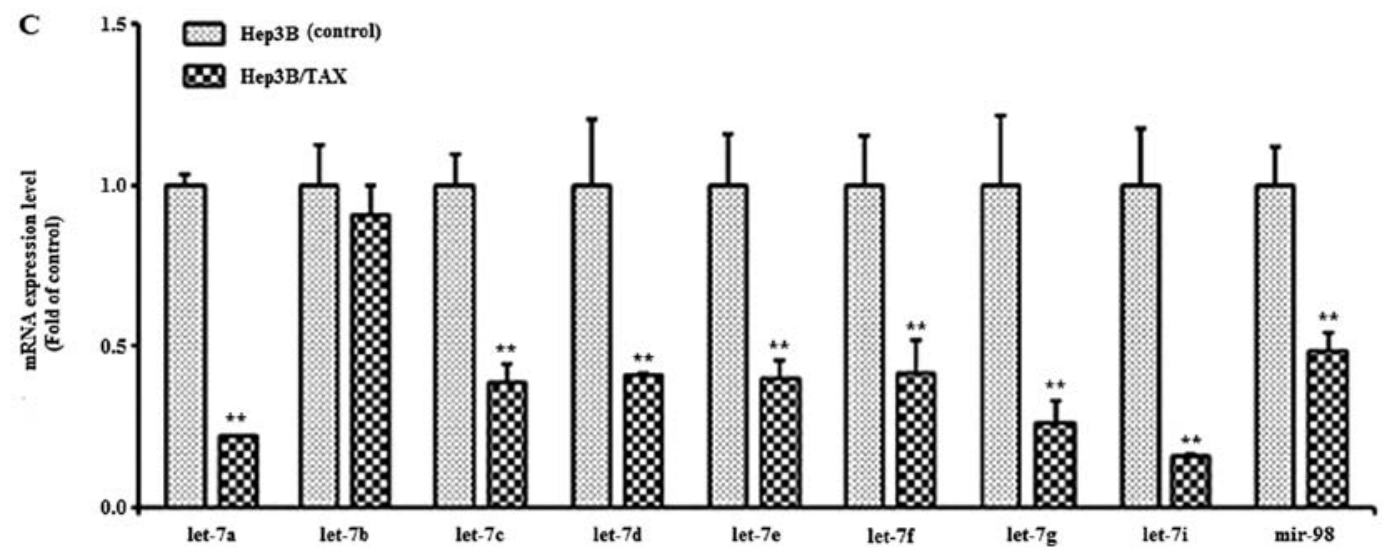

Figure 5. The expression of Lin28 and let-7 family in Hep3B and Hep3B/TAX cells. (A) Lin28 mRNA was examined by qPCR in Hep3B and Hep3B/TAX cells (B) Lin 28 expression was determined in Hep3B and Hep3B/TAX cells separately by western blotting; $\beta$-actin expression was used as a control. (C) Expression of let-7 family miRNAs by qPCR. ${ }^{* *} \mathrm{P}<0.001 \mathrm{Hep} 3 \mathrm{~B} / \mathrm{TAX}$ compared with Hep3B cells.

\section{Discussion}

Human cancer exhibits differential sensitivities to chemotherapeutic drugs, which is associated with the inherent sensitivity of their tissues of origin. Solid tumors, such as hepatocellular carcinoma (HCC), show a high degree of drug resistance due to poor drug uptake as well as intrinsic factors which regulate the cellular response to different drugs. Although a considerable research has been carried out, particularly on the overexpression of the P-glycoproteins which are encoded by the MDR1 class of genes (12-14), the micro-mechanism has not yet been fully elucidated. Therefore, in the present study, we established a drug-resistant cell line, Hep3B/TAX, using stepwise selection to explore the underlying mechanism of drug resistance in HCC cells.

We confirmed the drug-resistant phenotype by assessing the growth properties of Hep3B/TAX cells in comparison to the parental Hep3B cells. Although Hep3B/TAX cells doubled more slowly than Hep3B cells, the survival rate of Hep3B/TAX cells in the presence of paclitaxel was much higher than that of Hep3B cells. The $\mathrm{IC}_{50}$ value of paclitaxel for Hep3B/TAX was $5.65 \mu \mathrm{M}$, whereas that for Hep3B was only $0.2 \mu \mathrm{M}$ (the drug resistance index was 28.25). Additionally, Hep3B/TAX cells also exhibited resistance to cisplatin, 5-fluorouracil and cytoxan. This cross-resistance phenotype was also reported by other groups $(15,16)$. Next, we confirmed the drug resistance phenotype by measuring the induction of apoptosis in Hep3B/TAX cells following treatment with paclitaxel. The apoptosis rate in Hep3B/TAX cells was clearly lower than that in Hep3B cells after same dose paclitaxel treatment. Since caspases are situated at pivotal junctions in apoptosis, we examined the expression and cleavage of caspase- 9 and -3 in these two cell lines. The data suggest that the resistance of Hep3B/TAX cells to apoptosis associated with drug resistance and the caspases dependent mitochondrial intrinsic pathway since we observed a reduction in cytochrome $c$ release and cleavage of caspase- 9 and -3 , which act on the death substrates (17). In addition, the anti-apoptosis gene $\mathrm{Bcl}-2$ and the pro-apoptosis gene BAX were also involved (Bcl-2 was downregulated and BAX was upregulated in Hep3B/TAX cells).

Recently, the cancer stem cell marker Lin 28 has emerged as a contributor to drug resistance. It has been reported that Lin 28 expression is a possible mechanism of chemoresistance in breast cancer by targeting $\mathrm{p} 21, \mathrm{Rb}$ and let-7 miRNA (5). Teng et al (6) demonstrated the role of Lin28 in predicting the chemosensitivity of gastric cancer patients. In this study, we also found much higher Lin 28 mRNA and protein expression in the drug-resistant Hep3B/TAX cell line than in the parental cell line. Furthermore, the expression of let-7 family miRNAs, which are regulated by Lin28, were all reduced in Hep3B/ TAX cells except let-7b, and let-7i had the lowest expression. Liu et al also found that decreased expression of microRNA let-7i was associated with chemotherapeutic response in human gastric cancer (18). On the other hand, our results of the let-7 family showed a preference for interaction of let-7 microRNAs with Lin28. 
Previous studies demonstrated that $\mathrm{Bcl}-\mathrm{xL}$ was overexpressed in one-third of human HCC and that it was associated with drug resistance in hepatoma cells (19). Notably, it is negatively regulated by the let-7 family. Therefore, we measured the expression of Bcl-xL in Hep3B/TAX and Hep3B cells. Western blotting showed that the expression of Bcl-xL was significantly higher in Hep3B/TAX cells than in the parental Hep3B cells, suggesting its association with drug resistance in Hep3B cells. Bcl-xL is a well-known anti-apoptotic gene of the Bcl-2 family. Cancer cells frequently overexpress one or more members of this family to acquire a survival advantage (20). Therefore, we considered that overexpression of Lin28 induced downregulation of let-7 family microRNAs, which induced the overexpression of Bcl-xL. The overexpression of Bcl-xL allowed Hep3B/TAX cells to escape from apoptosis and acquire a survival advantage when treated with chemotherapeutic drugs.

In summary, the Lin28/let-7/Bcl-xL pathway may be an underlying mechanism of drug resistance of Hep3B cells. Our study provides valuable information for the improvement of chemotherapy in patients with HCC.

\section{Acknowledgements}

This study was supported in part by research grants from the Natural Science Foundation of Zhejiang Province, Youth Fund Project (no. LQ12C07001), and research fund for the Doctoral Program of Higher Education of China (no. 20133322120002).

\section{References}

1. Poon D, Anderson BO, Chen LT, et al: Management of hepatocellular carcinoma in Asia: consensus statement from the Asian Oncology Summit 2009. Lancet Oncol 10: 1111-1118, 2009.

2. Cammà C, Schepis F, Orlando A, Albanese M, Shahied L, Trevisani F, Andreone P, Craxì A and Cottone M: Transarterial chemoembolization for unresectable hepatocellular carcinoma: meta-analysis of randomized controlled trials. Radiology 224 : 47-54, 2002.

3. Lin HL, Lui WY, Liu TY and Chi CW: Reversal of Taxol resistance in hepatoma by cyclosporine A: involvement of the PI-3 kinase-AKT 1 pathway. Br J Cancer 88: 973-980, 2003.

4. Yang X, Lin X, Zhong X, et al: Double-negative feedback loop between reprogramming factor LIN28 and microRNA let-7 regulates aldehyde dehydrogenase 1-positive cancer stem cells. Cancer Res 70: 9463-9472, 2010.
5. Lv K1, Liu L, Wang L, et al: Lin28 mediates paclitaxel resistance by modulating $\mathrm{p} 21, \mathrm{Rb}$ and Let-7a miRNA in breast cancer cells. PLoS One 7: e 40008, 2012.

6. Teng RY, Zhou JC, Jiang ZN, Xu CY, Li ZD, Wang QC, Xu CP, Guo JF, Shen JG and Wang LB: The relationship between Lin28 and the chemotherapy response of gastric cancer. Onco Targets Ther 6: 1341-1345, 2013.

7. Viswanathan SR, Powers JT, Einhorn W, Hoshida Y, Ng TL, Toffanin S, et al: Lin28 promotes transformation and is associated with advanced human malignancies. Nat Genet 41: 843-848, 2009

8. Viswanathan SR, Daley GQ and Gregory RI: Selective blockade of microRNA processing by Lin28. Science 320: 97-100, 2008.

9. Heo I, Joo C, Cho J, Ha M, Han J and Kim VN: Lin28 mediates the terminal uridylation of let-7 precursor microRNA. Mol Cell 32: 276-284, 2008.

10. Shimizu S, Takehara T, Hikita $\mathrm{H}$, et al: The let-7 family of microRNAs inhibits Bcl-xL expression and potentiates sorafenib-induced apoptosis in human hepatocellular carcinoma. J Hepatol 52: 698-704, 2010.

11. Tian N, Li X, Luo Y, Han Z, Li Z and Fan C: Curcumin regulates the metabolism of low density lipoproteins by improving the C-to-U RNA editing efficiency of apolipoprotein B in primary rat hepatocytes. Mol Med Rep 9: 132-136, 2014.

12. Cavalieri EL, Stack DE, Devanesan PD, et al: Molecular origin of cancer: catechol estrogen-3,4-quinones as endogenous tumor initiators. Proc Natl Acad Sci USA 94: 10937-10942, 1997.

13. Kool M1, de Haas M, Scheffer GL, Scheper RJ, van Eijk MJ, Juijn JA, Baas F and Borst P: Analysis of expression of $c M O A T$ (MRP2), MRP3, MRP4, and MRP5, homologues of the multidrug resistance-associated protein gene $(M R P 1)$, in human cancer cell lines. Cancer Res 57: 3537-3547, 1997.

14. Lin HL, Liu TY, Lui WY and Chi CW: Up-regulation of multidrug resistance transporter expression by berberine in human and murine hepatoma cells. Cancer 85: 1937-1942, 1999.

15. Zhang J, Zhao J, Zhang W, Liu G, Yin D, Li J, Zhang S and Li H: Establishment of paclitaxel-resistant cell line and the underlying mechanism on drug resistance. Int $\mathrm{J}$ Cynecol Cancer 22: 1450-1456, 2012

16. Işeri OD, Kars MD, Eroglu S and Gündüz U: Drug resistant MCF-7 cell lines also developed cross-resistance to structurally unrelated anticancer agents. UHOD 19: 1-8, 2009.

17. Andersen MH, Becker JC and Straten Pt: Regulators of apoptosis: suitable targets for immune therapy of cancer. Nat Rev Drug Discov 4: 399-409, 2005.

18. Liu K, Qian T, Tang L, Wang J, Yang H and Ren J: Decreased expression of microRNA let-7 $\mathrm{i}$ and its association with chemotherapeutic response in human gastric cancer. World J Surg Oncol 10: 225, 2012

19. Takehara T, Liu X, Fujimoto J, Friedman SL and Takahashi H: Expression and role of Bcl-xL in human hepatocellular carcinomas. Hepatology 34: 55-61, 2001.

20. Lessene G, Czabotar PE and Colman PM: BCL-2 family antagonists for cancer therapy. Nat Rev Drug Discov 7: 989-1000, 2008. 